\title{
Clinical Predictors of the Hypoglycemic Effect of Sodium-Glucose Co-transporter-2 Inhibitors in Hyperuricemic Patients: A Retrospective Descriptive Observational Study
}

\author{
Toshinori Hirai, ${ }^{* a}$ Yuya Kawagoe, ${ }^{a}$ Motoki Kei, ${ }^{a}$ Ryuichi Ogawa, ${ }^{b}$ and Toshimasa Itoh $^{a}$ \\ ${ }^{a}$ Department of Pharmacy, Tokyo Women's Medical University Medical Center East; 2-1-10 Nishiogu, Arakawa-ku, \\ Tokyo 116-0011, Japan: and ${ }^{b}$ Department of Pharmacotherapy, Meiji Pharmaceutical University; 2-522-1 Noshio, \\ Kiyose, Tokyo 204-8588, Japan. \\ Received September 11, 2019; accepted February 6, 2020
}

\begin{abstract}
Sodium-glucose co-transporter-2 (SGLT2) inhibitors decrease glycated hemoglobin (HbA1c) and prevent the progression of cardiovascular and kidney diseases. Because uric acid and electrolytes are physiologically similar to blood glucose in renal excretion, we assessed predictors for the hypoglycemic effect of SGLT2 inhibitor treatment by focusing on serum uric acid and serum electrolytes. We performed a retrospective descriptive observational study at the Tokyo Women's Medical University, Medical Center East, from June 2015 to July 2018. Patients who received treatment with any type of SGLT2 inhibitor were selected, which included a total of $\mathbf{1 6 5}$ patients. The response to SGLT2 inhibitors defined as changes in HbA1c after SGLT2 inhibitor treatment was the main outcome measure. Multiple linear regression analysis was used to assess predictors for the hypoglycemic effect by SGLT2 inhibitors. Among the 165 patients, SGLT2 inhibitor treatment decreased HbA1c from 8.2 to $7.6 \%$ after 12 weeks $(p<0.01)$. Multiple linear regression analysis revealed that predictors of early response to SGLT2 inhibitors were serum uric acid values $(p=0.014)$ and baseline HbA1c $(p<0.001)$. Furthermore, late response to SGLT2 inhibitors was associated with serum uric acid value $(p=0.047)$ and baseline HbA1c $(p<0.001)$. Serum uric acid did not vary during SGLT2 inhibitor treatment; specifically, the SGLT2 inhibitors did not reduce serum uric acid levels. There was no correlation between changes in serum uric acid and HbA1c $(p=0.13)$. Thus, this study showed that serum uric acid value is associated with the control of diabetes mellitus during SGLT2 inhibitor treatment. Further studies are required to validate these results.
\end{abstract}

Key words sodium-glucose-co-transporter-2; hypoglycemic effect; uric acid; glycated hemoglobin

\section{INTRODUCTION}

Sodium-glucose co-transporter-2 (SGLT2) inhibitors enhance the excretion of blood glucose and decrease glycated hemoglobin (HbAlc). ${ }^{1,2}$ ) Randomized clinical trials have shown that SGLT2 inhibitors can reduce the incidence of cardiovascular and kidney events, such as hospitalization for heart failure and the progression of kidney disease. ${ }^{3-5)}$ In addition, SGLT2 inhibitors lower blood pressure and decrease body weight. ${ }^{6}$ Therefore, SGLT2 inhibitors are a theoretically preferable drug option for diabetic patients with hypertension and/or obesity.

The efficacy of SGLT2 inhibitors varies widely among individuals. ${ }^{7-9)}$ Furthermore, the incidence of side effects also differs substantially between individuals. ${ }^{9)}$ Thus, it is important to differentiate non/weak-responders from ideal responders to SGLT2 inhibitor therapy as soon as possible to maintain good risk/benefit balance of diabetes management. For instance, the development of serious adverse drug reactions such as euglycemic diabetic ketoacidosis and mycotic infections during ineffective treatment could outweigh the therapeutic benefits in non/weak-responders. ${ }^{10,11)}$ Yagi et al. demonstrated that the response to SGLT2 inhibitors differed according to patients' background. ${ }^{12)}$ High HbAlc and estimated glomerular filtration rate (eGFR) at the initiation of SGLT2 inhibitor therapy were predictors for the efficacy of SGLT2 inhibitors in that study. ${ }^{12)}$
A recent report demonstrated that SGLT2 inhibitors reduce serum uric acid levels as a result of glycosuria. ${ }^{13)}$ In addition, SGLT2 inhibitors affect serum electrolyte levels through diuretic and endocrinological effects. ${ }^{14)}$ Blood glucose kinetics resemble those of uric acid and electrolytes with respect to renal excretion mechanism by not only glomerular filtration but also by secretion and reabsorption via transporters. Glycosuria enhances the capacity of uric acid secretion via glucose transporter 9 isoform 2, which is correlated with serum uric acid concentration. ${ }^{13,15)}$ Here we hypothesized that uric acid and electrolytes are potential serum markers of a hypoglycemic response to SGLT2 inhibitors. The aim of our study was to investigate predictors routinely available for SGLT2 inhibitors with respect to hypoglycemic effect focusing on serum uric acid and serum electrolytes.

\section{PATIENTS AND METHODS}

Ethics Approval All procedures in this study involving human participants were performed in accordance with the ethical standards of the Institutional Review Board at Tokyo Women's Medical University (\#4920) and with the 1964 Helsinki Declaration and its later amendments.

Study Design and Patients This retrospective descriptive observational study was conducted at Tokyo Women's Medical University, Medical Center East from June 2015 to July 2018. Patients were included if they fulfilled inclusion criteria: 1) 
patients who had initiated treatment with an SGLT2 inhibitor (canagliflozin, empagliflozin, ipragliflozin, dapagliflozin, luseogliflozin, and tofogliflozin) during the study period and 2) patients whose HbAlc levels were available at the following three time points: i) the initiation of SGLT2 inhibitors, ii) within 4-12 weeks after the initiation, and iii) thereafter. Patients aged $<20$ years were excluded from our study population. We did not obtain informed consent from every single patient because this study design was a retrospective observational study. However, in compliance with the Clinical Trials Act in Japan, our study objective and target patients were disclosed inside the hospital to allow the target patients declining the use of their medical record. ${ }^{16)}$ This study protocol was approved by the Institutional Review Board at Tokyo Women's Medical University (\#4920).

Data Collection Electronic medical records were reviewed to collect patient background (sex, age, height, body weight, and body mass index), vital signs (systolic and diastolic blood pressure), clinical laboratory data (hematocrit, serum albumin, blood urea nitrogen (BUN), serum creatinine (Cr), eGFR, serum uric acid, aspartate aminotransferase, alanine aminotransferase, serum sodium, serum potassium, and $\mathrm{HbAlc}$ ), and medications of interest (hypoglycemic medications [biguanides, thioridazines, sulfonylureas, glinides, $\alpha$-glucosidase inhibitors, dipeptidyl peptidase IV inhibitors, glucagon-like peptide-1 receptor agonists, and insulin], antihypertensive medications [angiotensin-converting enzyme inhibitors/angiotensin II receptor blockers, calcium channel blockers, and $\beta$ blockers], and diuretics [loop diuretics, thiazide diuretics, aldosterone receptor antagonists, and tolvap$\tan ]$ ). We calculated eGFR using the prediction equation ${ }^{17)}$ and BUN to serum $\mathrm{Cr}$ ratio (BUN/Cr) as a marker of volume depletion. Chronic kidney disease was defined as eGFR $<60 \mathrm{~mL} / \mathrm{min} / 1.73 \mathrm{~m}^{2}$ according to clinical practice guidelines issued by the Japanese Society of Nephrology. ${ }^{17)}$

HbA1c Assessment HbAlc was classified into three categories according to the measurement date as follows; 1) at the initiation of SGLT2 inhibitors (baseline), 2) 4-12 weeks (early), and 3) 12 weeks after (late). Early and late responses to SGLT2 inhibitors were defined as absolute changes in HbAlc after 4-12 weeks and after 12 weeks, respectively. The equation for each response was as followed: HbAlc in each period - baseline HbA1c. Early response to SGLT2 inhibitors was set at after 4-12 weeks because approximately $50 \%$ of the maximum response for $\mathrm{HbAlc}$ was attained after 4-12 weeks in a previous study. ${ }^{18)}$ Late response to SGLT2 inhibitors was set after 12 weeks because a previous report showed the reduction of $\mathrm{HbAlc}$ plateaued after 12 weeks irrespective of renal function. ${ }^{18)}$ We did not use HbAlc after 0-4 weeks because HbAlc represents mean blood glucose levels over several months. ${ }^{19)}$ If a patient had multiple measurements of HbAlc at an early or late period during SGLT2 inhibitor treatment, we used the earliest HbA1c measurement in each period.

Statistical Analysis Continuous variables were expressed as mean and standard deviation or median and interquartile range (IQR) as appropriate and were compared using Student's $t$-test or Mann-Whitney's $U$-test. Categorical variables were expressed as numbers and percentages. Time-courses of clinical laboratory data of interest were evaluated with the Kruskal-Wallis test followed by the post-hoc Steel test because of non-parametric data. The control value was set at the baseline value when the post-hoc Steel test was performed.

Multiple linear regression analysis was used to investigate predictors for early and late response to SGLT2 inhibitors. Cohen's effect for size, probability level, and power level were set at $0.15,0.05$, and 0.80 , respectively. A sample size of at least 84 patients was required to perform multiple linear regression analysis on the assumption that four independent variables were included in the final model in this study. We regarded the early and late responses to SGLT2 inhibitors as dependent variables. Independent variables were patient background, vital signs, clinical laboratory data, presence of comorbidity, and medications. Serum sodium level was divided into two groups (serum sodium $<135 \mathrm{mEq} / \mathrm{L}$ or $\geq 135 \mathrm{mEq} / \mathrm{L}$ ) because serum sodium $<135 \mathrm{mEq} / \mathrm{L}$ is one of the characteristics in hypervolemia. ${ }^{20)}$ Univariate linear regression analysis was used to assess the relationship between early and late response to SGLT2 inhibitors and independent variables. Potential independent variables were regarded as those with a $p$ value $<0.10$. When there was significant multicollinearity, we chose one of them as the point of clinical importance. A stepwise forward selection method determined which independent variables were included for the final model and the adjusted coefficient of determination $\left(R^{2}\right)$ according to Akaike's In-

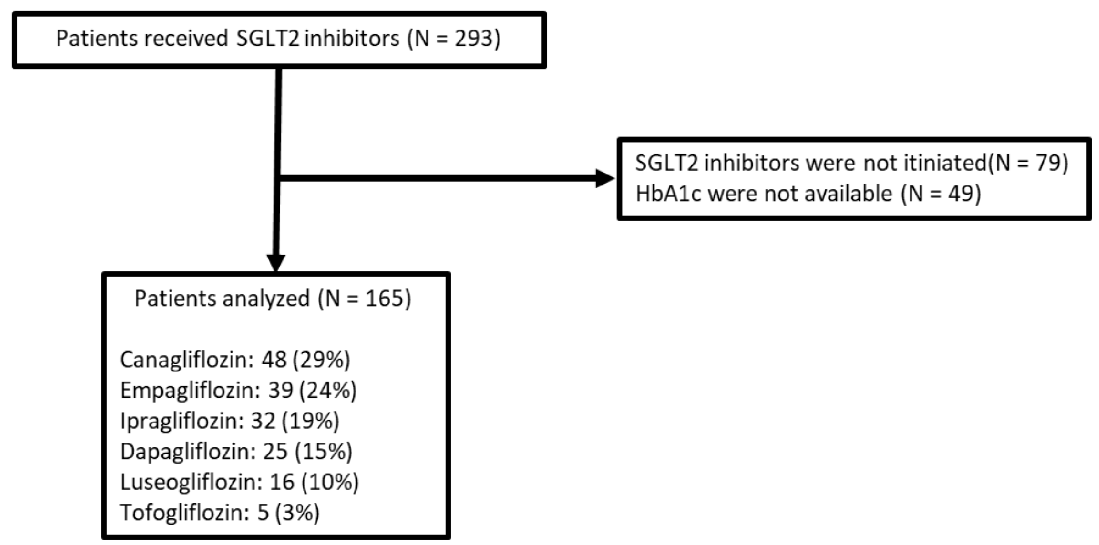

Fig. 1. Flow Chart of Patient Selection

At our institution, there were 293 patients who received SGLT2 inhibitors from June 2015 to July 2018 . We excluded 128 patients because 79 patients had not initiated SGLT2 inhibitor treatment at our hospital during the study period; while the remaining 49 had no data on HbAlc at baseline, early, or late time points. The remaining 165 patients were included in this study. Abbreviations: SGLT2, sodium-glucose co-transporter 2; HbA1c, glycated hemoglobin. 
formation Criterion (AIC). We assessed multiple regression equations and variance inflation factors. We performed an exploratory investigation of the relationship between changes in predictors and late response to SGLT2 inhibitor treatment using linear regression analysis.

Statistical analyses were carried out using JMP Pro 14 (SAS Institute, Cary, NC, U.S.A.). A $p$-value $<0.05$ was considered statistically significant unless otherwise noted.

Table 1. Patient Characteristics Prior to SGLT2 Inhibitor Treatment

\begin{tabular}{|c|c|}
\hline Characteristics (unit) & Value \\
\hline \multicolumn{2}{|l|}{ Demographical data } \\
\hline Number & 165 \\
\hline Male, $n(\%)$ & $106(64)$ \\
\hline Age (years) & $56.7 \pm 14.4$ \\
\hline Height (cm) & $164.2 \pm 8.8$ \\
\hline Body weight (kg) & $77.2 \pm 18.9$ \\
\hline Body mass index $\left(\mathrm{kg} / \mathrm{m}^{2}\right)$ & $28.5 \pm 5.6$ \\
\hline \multicolumn{2}{|l|}{ Vital signs } \\
\hline Systolic blood pressure $(\mathrm{mmHg})$ & $133 \pm 16$ \\
\hline Diastolic blood pressure $(\mathrm{mmHg})$ & $80 \pm 12$ \\
\hline \multicolumn{2}{|l|}{ Clinical laboratory data } \\
\hline Hematocrit (\%) & $43.5 \pm 4.3$ \\
\hline Serum albumin $(\mathrm{g} / \mathrm{dL})$ & $4.2 \pm 0.4$ \\
\hline Blood urea nitrogen $(\mathrm{mg} / \mathrm{dL})$ & $15.9 \pm 6.6$ \\
\hline Serum creatinine $(\mathrm{mg} / \mathrm{dL})$ & $0.84 \pm 0.27$ \\
\hline $\mathrm{eGFR}^{a)}\left(\mathrm{mL} / \mathrm{min} / 1.73 \mathrm{~m}^{2}\right)$ & $73.2 \pm 22.6$ \\
\hline $\mathrm{eGFR}^{a)}<60 \mathrm{~mL} / \mathrm{min} / 1.73 \mathrm{~m}^{2}, n(\%)$ & $33(20)$ \\
\hline Serum uric acid (mg/dL) & $5.7 \pm 1.6$ \\
\hline AST (IU/L) & $24[18-38]$ \\
\hline ALT (IU/L) & $29[19-51]$ \\
\hline Serum sodium $(\mathrm{mEq} / \mathrm{L})$ & $139 \pm 2.6$ \\
\hline Serum sodium $<135 \mathrm{mEq} / \mathrm{L}(\%)$ & $3(2)$ \\
\hline Serum potassium $(\mathrm{mEq} / \mathrm{L})$ & $4.2 \pm 0.4$ \\
\hline $\mathrm{HbAlc}(\%)$ & $8.2[7.6-9.5]$ \\
\hline $\mathrm{BUN} / \mathrm{Cr}$ & $19.6 \pm 6.5$ \\
\hline \multicolumn{2}{|l|}{ Medications of interest } \\
\hline Hypoglycemic medications, $n(\%)$ & $154(93)$ \\
\hline Biguanides, $n(\%)$ & $77(47)$ \\
\hline Thioridazines, $n(\%)$ & $37(22)$ \\
\hline Sulfonylureas, $n(\%)$ & $40(24)$ \\
\hline Glinides, $n(\%)$ & $17(10)$ \\
\hline$\alpha$-Glucosidase inhibitors, $n(\%)$ & $42(25)$ \\
\hline DPP IV inhibitors, $n(\%)$ & $122(74)$ \\
\hline GLP-1 receptor agonists, $n(\%)$ & $5(3)$ \\
\hline Insulin, $n(\%)$ & $38(23)$ \\
\hline Antihypertensive medications, $n(\%)$ & $102(62)$ \\
\hline $\mathrm{ACEi} / \mathrm{ARB}, n(\%)$ & $92(56)$ \\
\hline Calcium channel blockers, $n(\%)$ & $59(36)$ \\
\hline$\beta$ blockers, $n(\%)$ & $30(18)$ \\
\hline Diuretics, $n(\%)$ & $26(16)$ \\
\hline Loop diuretics, $n(\%)$ & $16(10)$ \\
\hline Thiazide diuretics, $n(\%)$ & $5(3)$ \\
\hline Aldosterone blockers, $n(\%)$ & $17(10)$ \\
\hline Tolvaptan, $n(\%)$ & $4(2)$ \\
\hline
\end{tabular}

Continuous variables are expressed as mean \pm standard deviation or median and [interquartile range] as appropriate. Categorical variables are expressed as number and percentage. Abbreviations: eGFR, estimated glomerular filtration rate; AST, aspartate aminotransferase; ALT, alanine aminotransferase; HbAlc, glycated hemoglobin; BUN/Cr, blood urea nitrogen to serum creatinine ratio; DPP IV, dipeptidyl peptidase IV; GLP-1, glucagon-like peptide-1; ACEi, angiotensin-converting enzyme inhibitors; $\mathrm{ARB}$, angiotensin II receptor blockers $a$ ): eGFR was calculated using the prediction equation.

\section{RESULTS}

A flow chart of patient selection is shown in Fig. 1. At our hospital, 293 patients received SGLT2 inhibitors from June 2015 to July 2018. We excluded 128 patients because 79 patients had not initiated SGLT2 inhibitor treatment at our hospital during the study period, and 49 patients did not have HbAlc level at baseline, early and late time points. All patients who received SGLT2 inhibitors in our hospital were aged $>20$ years. After applying all the inclusion/exclusion criteria, we included 165 patients in this study. Details of the SGLT2 inhibitors used by these patients were as follows: canagliflozin, 48 (29\%); empagliflozin, 39 (24\%); ipragliflozin, 32 (19\%); dapagliflozin, 25 (15\%); luseogliflozin, 16 (10\%); and tofogliflozin, $5(3 \%)$. Clinical patient data prior to SGLT2 inhibitor treatment are summarized in Table 1.

The median (IQR) measurement date for early and late time points were 36 (30-53) days and 103 (91-119) days after the initiation of SGLT2 inhibitor treatment, respectively. The time-course of HbAlc measurement is shown in Fig. 2. HbA1c (IQR) at baseline was 8.2\% (7.6-9.5\%). SGLT2 inhibitor treatment consistently decreased compared to baseline HbAlc (Kruskal-Wallis test, $p<0.01$ ). HbAlc (IQR) at early and late time points was $7.9 \%(7.3-8.7 \%)$ (vs. at baseline, $p=0.03$ [Steel test]) and 7.6\% (6.9-8.5\%) (vs. at baseline, $p<0.01$ [Steel test]), respectively.

For early response to SGLT2 treatment, univariate linear regression analysis demonstrated that male gender, age, body mass index, hematocrit, eGFR, serum uric acid, serum sodium, baseline $\mathrm{HbAlc}, \mathrm{BUN} / \mathrm{Cr}$, and use of diuretics were potential independent variables. There was no multicollinearity between independent variables. A stepwise forward selection method determined that hematocrit, serum uric acid, and baseline HbAlc were included in the final model (Table 2). The multiple regression equation is as follows: early response to SGLT2 inhibitors $=0.40+0.03 \times$ hematocrit $+0.14 \times$ serum uric acid $-0.35 \times$ baseline HbAlc $\left(\mathrm{AIC}=143.1, \quad R^{2}=0.47\right.$, $p<0.001)$.

Alternatively, for the late response to SGLT2 treatment, univariate linear regression analysis demonstrated that male

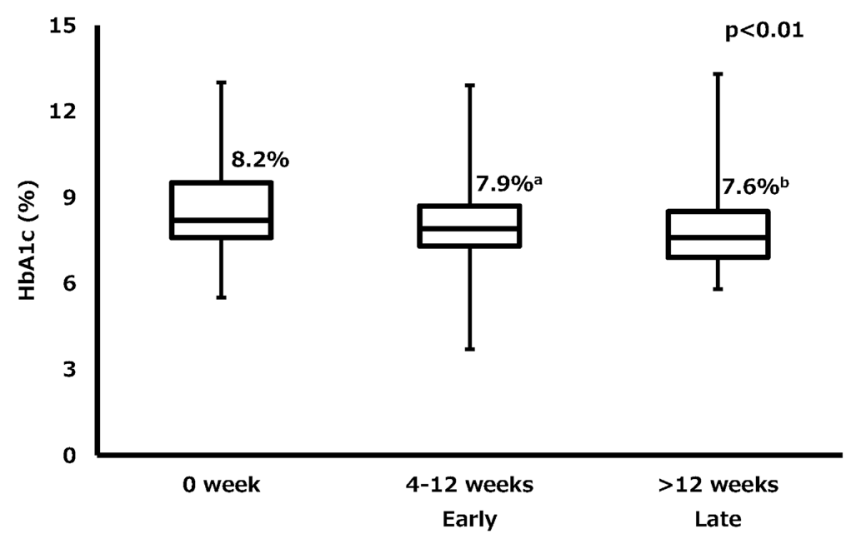

Fig. 2. Time-Course of HbA1c during SGLT2 Inhibitor Treatment

HbAlc is depicted by box and whisker plot. Upper and lower box borders are at the 75 and 25 percentiles. The middle bar is at the median value. Upper and lower whiskers are maximum and minimum values. The Kruskal-Wallis test was used to determine the $p$ value. a: $p=0.03, v s$. HbAlc at baseline tested by Kruskal-Wallis test followed by post-hoc Steel test, b: $p<0.01$, vs. HbA1c at baseline tested by the Kruskal-Wallis test followed by the post-hoc Steel test. Abbreviation: HbAlc, glycated hemoglobin. 
Table 2. Multiple Linear Regression Analysis for Early Response to SGLT2 Inhibitors

\begin{tabular}{l|cccccc}
\hline \hline Variable & $\beta$ & Estimate & S.E. & $95 \%$ CI & $p$ Value & VIF \\
\hline Intercept & 0 & 0.40 & 1.06 & $-1.71-2.51$ & 0.707 \\
Hematocrit (per \%) & 0.14 & 0.03 & 0.02 & $-0.01-0.07$ & 0.143 \\
Serum uric acid (per mg/dL) & 0.24 & 0.14 & 0.06 & $0.03-0.26$ & 1.02 \\
Baseline HbAlc (per \%) & -0.58 & -0.35 & 0.06 & $-0.46--0.24$ & $<0.014$ & 1.05 \\
\hline
\end{tabular}

Abbreviations: $\beta$, standardized partial regression coefficient; S.E., standard error of estimate; $95 \%$ CI, $95 \%$ confidence interval; VIF, variance inflation factor; NA, not applicable; HbA1c, glycated hemoglobin.

Table 3. Multiple Linear Regression Analysis for Late Response to SGLT2 Inhibitors

\begin{tabular}{l|cccccc}
\hline \hline Variable & $\beta$ & Estimate & S.E. & $95 \%$ CI & $p$ Value & VIF \\
\hline Intercept & 0 & 2.74 & 0.73 & $1.29-4.19$ & $<0.001$ \\
Serum uric acid (per mg/dL) & 0.15 & 0.13 & 0.06 & $0.00-0.25$ & 0.047 \\
Baseline HbA1c (per \%) & -0.58 & -0.49 & 0.06 & $-0.62--0.37$ & $<0.001$ & 1.05 \\
\hline
\end{tabular}

Abbreviations: $\beta$, standardized partial regression coefficient; S.E., standard error of estimate; $95 \%$ CI, $95 \%$ confidence interval; VIF, variance inflation factor; NA, not applicable; HbA1c, glycated hemoglobin.

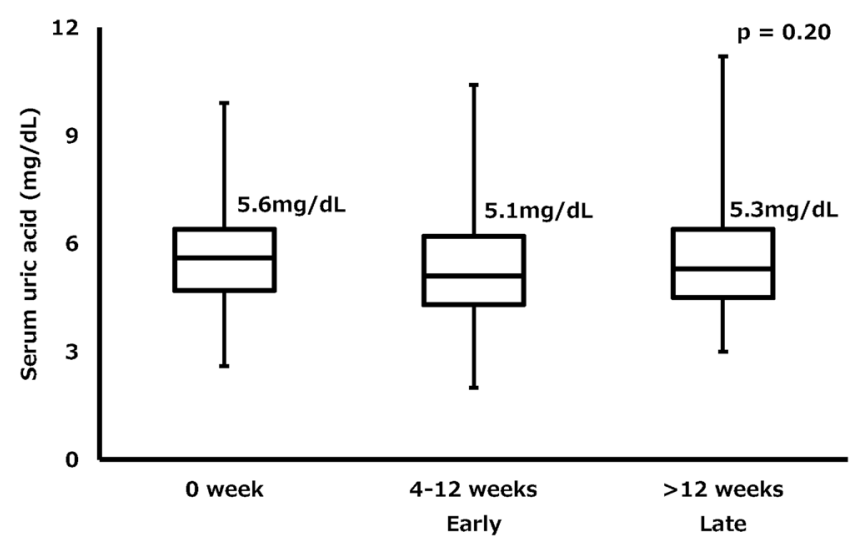

Fig. 3. Time-Course of Serum Uric Acid during SGLT2 Inhibitor Treatment

Serum uric acid value is depicted by box and whisker plot. Upper and lower box borders are at the 75 and 25 percentiles. The middle bar is at the median value. Upper and lower whiskers are maximum and minimum values. The Kruskal-Wallis test was used to determine the $p$ value.

gender, BUN, eGFR, serum uric acid, baseline HbA1c, and $\mathrm{BUN} / \mathrm{Cr}$ were potential independent variables. There was no multicollinearity between independent variables. Serum uric acid and baseline HbAlc were predictors for the late response to SGLT2 inhibitors as they were with the early response to SGLT2 inhibitors (Table 3). The multiple regression equation is as follows: late response to SGLT2 inhibitors $=2.74+0.13 \times$ serum uric acid $-0.49 \times$ baseline $\mathrm{HbAlc}$ $\left(\mathrm{AIC}=326.8, R^{2}=0.39, p<0.001\right)$.

SGLT2 inhibitors did not reduce serum uric acid values during SGLT2 inhibitor treatment (Fig. 3, Kruskal-Wallis test, $p=0.20$ ). Serum uric acid values (IQR) at baseline, early, and late time points were $5.6 \mathrm{mg} / \mathrm{dL}(4.7-6.4 \mathrm{mg} / \mathrm{dL}), 5.1 \mathrm{mg} / \mathrm{dL}$ $(4.3-6.2 \mathrm{mg} / \mathrm{dL})$, and $5.3 \mathrm{mg} / \mathrm{dL}(4.5-6.4 \mathrm{mg} / \mathrm{dL})$, respectively. Moreover, there was no significant relationship between changes in serum uric acid and HbAlc at the late time point (Fig. 4, $R=0.14, p=0.13$ ).

\section{DISCUSSION}

This study showed that serum uric acid is a predictor of

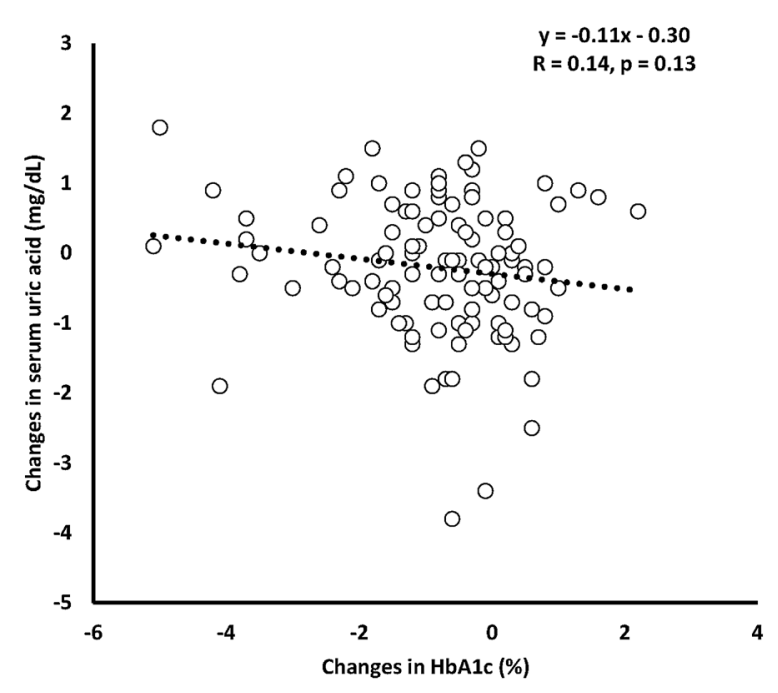

Fig. 4. Correlation between Changes in Serum Uric Acid and HbAlc at the Late Time Point

$X$-Axis and $Y$-axis represent changes in HbAlc and serum uric acid, respectively. An open circle represents each measured point. The dashed line represents the linear regression analysis result.

response to SGLT2 inhibitors irrespective of the time frame of SGLT2 inhibitor therapy, which agrees with our hypothesis. In addition, baseline HbA1c influenced the response to SGLT2 inhibitor treatment.

SGLT2 inhibitors reduced HbA1c approximately $0.5 \%$ on average at the plateau period in this study. This hypoglycemic effect is similar to that found in several clinical trials. ${ }^{1)}$ High baseline eGFR is associated with a greater response to SGLT2 inhibitors. ${ }^{12,21)}$ In addition, a previous research demonstrated that the higher body mass index, the greater hypoglycemic effect by SGLT2 inhibitors in patients with uncontrolled diabetes. ${ }^{21)}$ Therefore, the patients in our study had a favorable sensitivity to SGLT2 inhibitor treatment because the majority of patients had an eGFR $\geq 60 \mathrm{~mL} / \mathrm{min} / 1.73 \mathrm{~m}^{2}$ and body mass index $\geq 25 \mathrm{~kg} / \mathrm{m}^{2}$.

There was a weak correlation between baseline hematocrit value and early response to SGLT2 inhibitors, though this was not statistically significant. Previous research demonstrated 
that HbAlc is associated with hematocrit and hemoglobin. ${ }^{22)}$ Thus, it is conceivable that low hematocrit values from iron deficiency, anemia, or renal anemia can influence hemoglobin turnover, thereby lowering baseline HbAlc. Therefore, hematocrit values may be a useful marker of SGLT2 inhibitor efficacy.

As we proposed in our hypothesis, we demonstrated that patients with high serum uric acid concentration had a poor response to SGLT2 inhibitors, that is, the reduction of $\mathrm{HbAlc}$ was impaired in cases of hyperuricemia. Furthermore, serum uric acid concentration is regulated by a variety of physiological factors such as renal function, volume fluid balance, and dietary habit. ${ }^{23)}$ Indeed, there was an inverse correlation between serum uric acid and eGFR (data not shown) in this study. This relationship between serum uric acid and eGFR is compatible with a different study showing the efficacy of SGLT2 inhibitors is lowered in patients with renal impairment. ${ }^{18)}$ In addition, high serum uric acid concentration indicates extracellular volume depletion. ${ }^{24,25)}$ Because SGLT2 inhibitors have a diuretic effect, it is assumed that patients with hypovolemia experience less of a hypoglycemic effect when receiving SGLT2 inhibitor treatment. Although the details of food intake were unknown, serum uric acid might be a marker for renal function and fluid balance to identify a response to SGLT2 inhibitors.

Many studies have demonstrated that the baseline HbAlc is correlated with the efficacy of SGLT2 inhibitors and other antidiabetic medications, ${ }^{12,21,26,27)}$ which is in consistence with our results. Thus, assessment of baseline HbAlc is essential for clinicians to determine the response to SGLT2 inhibitors as well as other antidiabetic medications. In addition, knowing the types of oral hypoglycemic medications used concomitantly should be paid attention to achieve better glycemic control in clinical practice. Indeed, previous observational studies showed that concurrent use of SGLT2 inhibitors with metformin or dipeptidyl peptidase IV inhibitors achieved better glycemic control than other combinations. ${ }^{28,29)}$ However, combination therapy of SGLT2 inhibitors with other oral hypoglycemic medications was not seen in our multivariate analysis as a statistically significant predictor since about $90 \%$ patients received various types of hypoglycemic medications. Thus, we did not further analyze the difference in glycemic control among the different types of drug combinations to avoid type I statistical errors. The hypoglycemic effect was comparable regardless of concurrent use of hypoglycemic medications in our study population without any statistical adjustments (data not shown). In EMPA-REG OUTCOME study, there were no significant interactions between cardiovascular outcome and concomitant oral hypoglycemic medications ${ }^{3)}$ though the incidence of cardiovascular disease is generally higher in severely diabetic patients who are receiving multiple oral hypoglycemic medications. $^{30,31)}$

Although SGLT2 inhibitors have no influence on serum uric acid value, a meta-analysis demonstrated that SGLT2 inhibitors have a weak hypouricemic effect of $0.63 \mathrm{mg} / \mathrm{dL}^{32}$ ) This difference is attributed to the fact that Asian patients experience a relatively small hypouricemic effect compared to Caucasian patients. ${ }^{32)}$ Since Arg265His polymorphism of glucose transporter 9 isoform 2 was associated with racial difference regarding gout, ${ }^{33)}$ hypouricemic effect of SGLT2 inhibitors may also vary based on this polymorphism. It remains unclear whether this polymorphism affects the relationship between glucose lowering effect of SGLT2 inhibitors and serum uric acid. Further genetic studies are required to address this matter. Moreover, the decrease in serum uric acid depends on the baseline serum uric acid level. ${ }^{34)}$ However, there was no notable difference in baseline serum uric acid value between our study patients and patients in other studies. ${ }^{32}$ Furthermore, we did not observe a correlation between changes in serum uric acid and HbAlc. Additional studies are warranted to clarify this disparity between changes in blood glucose and serum uric acid.

Study results should be interpreted with regard to the presence of several limitations. First, this was a retrospective, single-institution study with small sample size. Second, we could not collect data such as dietary habit, alcohol consumption, compliance with pharmacotherapy, and other electrolytes (e.g., magnesium and phosphate) from electronic medical records. Third, we could not avoid using BUN/Cr and serum sodium $<135 \mathrm{mEq} / \mathrm{L}$ as an alternative index of hypovolemia and hypervolemia. Fourth, since there were few lean patients (i.e., body mass index $<18.5 \mathrm{~kg} / \mathrm{m}^{2}$ ) in our study population, our results should be interpreted that the final model could predict the early and late responses best in relatively overweight patients. Fifth, we were not able to perform urine examination to determine the excretion rate of uric acid and glucose. Finally, there were no patients with type 1 diabetes mellitus because this study was approved before we could include additional indications of type 1 diabetes mellitus.

\section{CONCLUSION}

In conclusion, serum uric acid and HbAlc at the time of treatment initiation with SGLT2 inhibitors were predictors for the response to SGLT2 inhibitors during treatment. Clinicians should consider the background of high serum uric acid value in patients taking SGLT2 inhibitors. Further studies are required to validate these results.

Acknowledgments Financial support was not provided for this study.

Conflict of Interest The authors declare no conflict of interest.

\section{REFERENCES}

1) Tang H, Cui W, Li D, Wang T, Zhang J, Zhai S, Song Y. Sodiumglucose co-transporter 2 inhibitors in addition to insulin therapy for management of type 2 diabetes mellitus: A meta-analysis of randomized controlled trials. Diabetes Obes. Metab., 19, 142-147 (2017).

2) Kalra S. Sodium glucose co-transporter-2 (SGLT2) inhibitors: a review of their basic and clinical pharmacology. Diabetes Ther., 5 355-366 (2014).

3) Zinman B, Wanner C, Lachin JM, Fitchett D, Bluhmki E, Hantel S, Mattheus M, Devins T, Johansen OE, Woerle HJ, Broedl UC, Inzucchi SE. Empagliflozin, cardiovascular outcomes, and mortality in type 2 diabetes. N. Engl. J. Med., 373, 2117-2128 (2015).

4) Wanner C, Inzucchi SE, Lachin JM, Fitchett D, von Eynatten M, Mattheus M, Johansen OE, Woerle HJ, Broedl UC, Zinman B. Empagliflozin and progression of kidney disease in type 2 diabetes. $N$. Engl. J. Med., 375, 323-334 (2016). 
5) Neal B, Perkovic V, Mahaffey KW, de Zeeuw D, Fulcher G, Erondu N, Shaw W, Law G, Desai M, Matthews DR. Canagliflozin and cardiovascular and renal events in type 2 diabetes. N. Engl. J. Med., 377, 644-657 (2017).

6) Cherney DZI, Cooper ME, Tikkanen I, Pfarr E, Johansen OE, Woerle HJ, Broedl UC, Lund SS. Pooled analysis of Phase III trials indicate contrasting influences of renal function on blood pressure, body weight, and HbA1c reductions with empagliflozin. Kidney Int., 93, 231-244 (2018)

7) Li J, Gong Y, Li C, Lu Y, Liu Y, Shao Y. Long-term efficacy and safety of sodium-glucose cotransporter-2 inhibitors as add-on to metformin treatment in the management of type 2 diabetes mellitus: a meta-analysis. Medicine (Baltimore), 96, e7201 (2017).

8) Rådholm K, Wu JH, Wong MG, Foote C, Fulcher G, Mahaffey $\mathrm{KW}$, Perkovic V, Neal B. Effects of sodium-glucose cotransporter-2 inhibitors on cardiovascular disease, death and safety outcomes in type 2 diabetes - a systematic review. Diabetes Res. Clin. Pract., 140, 118-128 (2018).

9) Toyama T, Neuen BL, Jun M, Ohkuma T, Neal B, Jardine MJ, Heerspink HL, Wong MG, Ninomiya T, Wada T, Perkovic V. Effect of SGLT2 inhibitors on cardiovascular, renal and safety outcomes in patients with type 2 diabetes mellitus and chronic kidney disease: a systematic review and meta-analysis. Diabetes Obes. Metab., 21, 1237-1250 (2019).

10) Peters AL, Buschur EO, Buse JB, Cohan P, Diner JC, Hirsch IB. Euglycemic diabetic ketoacidosis: a potential complication of treatment with sodium-glucose cotransporter 2 inhibition. Diabetes Care, 38, 1687-1693 (2015).

11) Adimadhyam S, Schumock GT, Calip GS, Smith Marsh DE, Layden BT, Lee TA. Increased risk of mycotic infections associated with sodium-glucose co-transporter 2 inhibitors: a prescription sequence symmetry analysis. Br. J. Clin. Pharmacol., 85, 160-168 (2019).

12) Yagi S, Aihara KI, Kondo $T$, et al. Predictors for the treatment effect of sodium glucose co-transporter 2 inhibitors in patients with type 2 diabetes mellitus. Adv. Ther., 35, 124-134 (2018).

13) Chino Y, Samukawa Y, Sakai S, Nakai Y, Yamaguchi J, Nakanishi T, Tamai I. SGLT2 inhibitor lowers serum uric acid through alteration of uric acid transport activity in renal tubule by increased glycosuria. Biopharm. Drug Dispos., 35, 391-404 (2014).

14) Filippatos TD, Tsimihodimos V, Liamis G, Elisaf MS. SGLT2 inhibitors-induced electrolyte abnormalities: an analysis of the associated mechanisms. Diabetes Metab. Syndr., 12, 59-63 (2018).

15) Testa A, Mallamaci F, Spoto B, Pisano A, Sanguedolce MC, Tripepi G, Leonardis D, Zoccali C. Association of a polymorphism in a gene encoding a urate transporter with CKD progression. Clin. J. Am. Soc. Nephrol., 9, 1059-1065 (2014)

16) “Clinical Trials Act in JAPAN.”: 〈https://www.mhlw.go.jp/file/06Seisakujouhou-10800000-Iseikyoku/0000213334.pdf), accessed 16 August, 2019

17) Matsuo S, Imai E, Horio $M$, Yasuda $Y$, Tomita $K$, Nitta $K$, Yamagata $\mathrm{K}$, Tomino Y, Yokoyama H, Hishida A. Revised equations for estimated GFR from serum creatinine in Japan. Am. J. Kidney Dis., 53, 982-992 (2009).

18) Petrykiv S, Sjöström CD, Greasley PJ, Xu J, Persson F, Heerspink HJL. Differential effects of dapagliflozin on cardiovascular risk factors at varying degrees of renal function. Clin. J. Am. Soc. Nephrol., 12, 751-759 (2017).

19) Sherwani SI, Khan HA, Ekhzaimy A, Masood A, Sakharkar MK. Significance of HbAlc test in diagnosis and prognosis of diabetic patients. Biomark. Insights, 11, 95-104 (2016).

20) Lim LM, Tsai NC, Lin MY, Hwang DY, Lin HY, Lee JJ, Hwang SJ, Hung CC, Chen HC. Hyponatremia is associated with fluid imbal- ance and adverse renal outcome in chronic kidney disease patients treated with diuretics. Sci. Rep., 6, 36817 (2016).

21) Lee JY, Cho Y, Lee M, Kim YJ, Lee YH, Lee BW, Cha BS, Kang ES. Predictors of the therapeutic efficacy and consideration of the best combination therapy of sodium-glucose co-transporter 2 inhibitors. Diabetes Metab. J., 43, 158-173 (2019).

22) Abass AE, Musa IR, Rayis DA, Adam I, Gasim I G. Glycated hemoglobin and red blood cell indices in non-diabetic pregnant women. Clin. Pract., 7, 999 (2017).

23) Rees F, Hui M, Doherty M. Optimizing current treatment of gout. Nat. Rev. Rheumatol., 10, 271-283 (2014).

24) Liamis G, Christidis D, Alexandridis G, Bairaktari E, Madias NE, Elisaf M. Uric acid homeostasis in the evaluation of diureticinduced hyponatremia. J. Investig. Med., 55, 36-44 (2007).

25) Musch W, Decaux G. Utility and limitations of biochemical parameters in the evaluation of hyponatremia in the elderly. Int. Urol. Nephrol., 32, 475-493 (2001).

26) Kuwata H, Okamoto S, Seino Y, Murotani K, Tatsuoka H, Usui R, Hamamoto Y, Kurose T, Seino Y, Yabe D. Relationship between deterioration of glycated hemoglobin-lowering effects in dipeptidyl peptidase-4 inhibitor monotherapy and dietary habits: Retrospective analysis of Japanese individuals with type 2 diabetes. J. Diabetes Investig., 9, 1153-1158 (2018).

27) Dahlqvist S, Ahlen E, Filipsson K, Gustafsson T, Hirsch IB, Tuomilehto J, Imberg H, Ahren B, Attvall S, Lind M. Variables associated with $\mathrm{HbAlc}$ and weight reductions when adding liraglutide to multiple daily insulin injections in persons with type 2 diabetes (MDI Liraglutide trial 3). BMJ Open Diabetes Res. Care, 6, e000464 (2018).

28) Thewjitcharoen Y, Yenseung N, Malidaeng A, Nakasatien S, Chotwanvirat P, Krittiyawong S, Wanothayaroj E, Himathongkam T. Effectiveness of long-term treatment with SGLT2 inhibitors: realworld evidence from a specialized diabetes center. Diabetol. Metab. Syndr., 9, 96 (2017).

29) Wilding J, Godec T, Khunti K, Pocock S, Fox R, Smeeth L, Clauson P, Fenici P, Hammar N, Medina J. Changes in HbAlc and weight, and treatment persistence, over the 18 months following initiation of second-line therapy in patients with type 2 diabetes: results from the United Kingdom Clinical Practice Research Datalink. BMC Med., 16, 116 (2018).

30) Andersson C, van Gaal L, Caterson ID, Weeke P, James WP, Couthino W, Finer N, Sharma AM, Maggioni AP, Torp-Pedersen C. Relationship between HbA1c levels and risk of cardiovascular adverse outcomes and all-cause mortality in overweight and obese cardiovascular high-risk women and men with type 2 diabetes. Diabetologia, 55, 2348-2355 (2012).

31) Selvin E, Ning Y, Steffes MW, Bash LD, Klein R, Wong TY, Astor BC, Sharrett AR, Brancati FL, Coresh J. Glycated hemoglobin and the risk of kidney disease and retinopathy in adults with and without diabetes. Diabetes, 60, 298-305 (2011).

32) Zhao Y, Xu L, Tian D, Xia P, Zheng H, Wang L, Chen L. Effects of sodium-glucose co-transporter 2 (SGLT2) inhibitors on serum uric acid level: a meta-analysis of randomized controlled trials. Diabetes Obes. Metab., 20, 458-462 (2018).

33) Hollis-Moffatt JE, Gow PJ, Harrison AA, Highton J, Jones PB, Stamp LK, Dalbeth N, Merriman TR. The SLC2A9 nonsynonymous Arg265His variant and gout: evidence for a population-specific effect on severity. Arthritis Res. Ther., 13, R85 (2011).

34) Hao Z, Huang X, Shao H, Tian F. Effects of dapagliflozin on serum uric acid levels in hospitalized type 2 diabetic patients with inadequate glycemic control: a randomized controlled trial. Ther. Clin. Risk Manag., 14, 2407-2413 (2018). 